\title{
Combining bibliometrics and information retrieval: preface
}

\author{
Philipp Mayr • Andrea Scharnhorst
}

Received: 18 December 2014/ Published online: 24 January 2015

(C) Akadémiai Kiadó, Budapest, Hungary 2015

This special issue brings together eight papers from experts of communities which often have been perceived as different once: bibliometrics, scientometrics and informetrics on the one side and information retrieval on the other. The idea of this special issue started at the workshop "Combining Bibliometrics and Information Retrieval" held at the 14th International Conference of Scientometrics and Informetrics, Vienna, July 14-19, 2013. Our motivation as guest editors started from the observation that main discourses in both fields are different, that communities are only partly overlapping and from the belief that a knowledge transfer would be profitable for both sides. Hereby, we were inspired by the bibliometric analysis of the broader field of Library and Information Science done by White and McCain (1998).

The discussions during the ISSI workshop in Vienna and the papers in this special issue highlighted the following features of distinction:

- The audiences served by IR and scientometrics are very different. The former focuses on users of information systems as implemented on the web, in libraries and archives, the latter-in its form of evaluative bibliometrics-addresses primarily research manager and science policy makers in universities, funding agencies and ministries.

- With these different audiences come also different goals towards which algorithms of information processing used in both fields are tailored. IR supports an individual user to find paths through knowledge spaces. While devoted to an as good as possible match between search terms and materials in the collection at hand, serendipity and large coverage of the retrieved set of documents are not unwelcome features. For the evaluation of research groups the goal is to delineate the field of relevant works as sharp and precisely as possible.

P. Mayr $(\bowtie)$

GESIS-Leibniz-Institute for the Social Sciences, Cologne, Germany

e-mail: philipp.mayr@gesis.org

A. Scharnhorst

Royal Netherlands Academy of Arts and Sciences (DANS), Amsterdam, Netherlands 
- The scale and nature of the collections or information spaces upon which IR or scientometrics/bibliometrics operate can be different. Information retrieval is not only applied for scholarly communication and related bibliographic databases. Its application area encompasses intelligence, business information, library catalogues, collections of musea and libraries, and the world-wide web as a whole (search engines). In contrast, scientometrics mainly operates in the world of journal articles, and only more recently opened towards scholarly communication on the web (webometrics and altmetrics).

- The educational paths towards IR and bibliometrics are different to some extent. This accounts further for the gap between IR and bibliometrics in fundamental research. In universities IR can be found as part both of Computer Sciences as well as of iSchools or Information Schools. Bibliometrics and Scientometrics are far less established in standard university curricula.

This special issue invites the reader to do no less, to read the accounts of different scholars in the field, their perception of links between IR and scientometrics, and their identification of promising future lines of research and collaboration.

\section{Reference}

White, H. D., \& McCain, K. W. (1998). Visualizing a discipline: An author co-citation analysis of information science, 1972-1995. Journal of the American Society for Information Science, 49, 327-355. 